Горбань Александр Сергеевич

преподаватель кафедры криминалистики и правовой информатики

Кубанского государственного университета

\section{НАЧАЛЬНЫЙ ЭТАП РАССЛЕДОВАНИЯ НАРКОПРЕСТУПЛЕНИЙ ПРИ ПРОИЗВОДСТВЕ ДОЗНАНИЯ В СОКРАЩЕННОЙ ФОРМЕ}

\section{Аннотация:}

При расследовании преступлений, предусмотренных в ч. $1 \mathrm{~cm}$. 228 УК РФ, дознаватели наиболее часто прибегают к установленной в Уголовно-процессуальном кодексе РФ возможности его реализации в сокращенной форме. Вместе с тем изучение материалов правоприменительной практики свидетельствует о незначительных сокращениях сроков расследования, детерминированных разными причинами. В связи с этим с опорой на теоретические рекомендации и правоприменительную практику в статье предложена программа действий для этапа рассмотрения сообщения о преступлении в целях организации последовательности проверочных и следственных действий. Данная последовательность мероприятий позволяет окончить его в установленный законом срок, а также снабдить дознавателя криминалистически значимой информацией и доказательствами, на базе которых можно судить о перспективе использования сокращенной формы дознания.

Ключевые слова:

сокращенная форма дознания, организация расследования преступлений, начальный этап расследования, программа расследования.
Gorban Alexander Sergeyevich

Lecturer, Criminalistics and Legal Informatics Subdepartment, Kuban State University \section{INVESTIGATING THE DRUG OFFENSES DURING THE INQUIRY IN AN ABBREVIATED FORM}

Summary:

When investigating crimes under Part 1 of Article 228 of the Criminal Code of the Russian Federation, the investigators often recourse to its implementation in an abbreviated form set forth in the Russian Federation Code of Criminal Procedure. At the same time, studying the materials of law enforcement practice demonstrates the insignificant reduction of investigation period determined by various reasons. In this regard, based on theoretical recommendations and law enforcement practice, the author proposes a course of actions for reviewing a crime report in order to organize consistent verification and investigation. Consistent actions will allow one to complete investigation within the statutory period. Moreover, they will provide the investigator with forensic information and evidence. In sum, it will show the prospect of applying inquiry in an abbreviated form.

Keywords: inquiry in an abbreviated form, organization of crime investigation, initial stage of investigation, investigation program.

За время существования сокращенного порядка дознания авторы публикаций в периодических изданиях вполне справедливо обращали внимание на разные проблемы и пробелы при его реализации на практике. Отсюда неизбежно следует вопрос о том, возможно ли найти баланс между действиями, предпринимаемыми в ходе рассмотрения сообщения о преступлении, и действиями, которые будут производиться дознавателем после возбуждения и получения материалов уголовного дела. Изучением востребованности и эффективности сокращенных форм расследования занимаются также зарубежные исследователи [1].

В связи с изложенным, с опорой на учение об организации расследования преступлений, а также на основе 50 материалов уголовных дел, расследованных сотрудниками правоохранительных органов г. Краснодара и Краснодарского края в сокращенной форме дознания, далее предложена программа по расследованию преступлений, предусмотренных в ч. 1 ст. 228 УК РФ. Изложенная программа большей частью предназначена для доследственных ситуаций [2]. Последовательное выполнение ее действий позволит своевременно и полно обнаружить и зафиксировать необходимую доказательственную информацию, спрогнозировать выражение подозреваемым согласия на производство сокращенной формы дознания и его производство в установленный в ст. 226.6 УПК РФ срок и ранее.

В соответствии со Сведениями о результатах работы подразделений дознания по уголовным делам, расследование которых производилось в сокращенной форме, преступления, связанные с незаконным оборотом наркотических, психотропных и сильнодействующих веществ, в частности предусмотренных в ч. 1 ст. 228 УК РФ, представлены в большом количестве. 3 а 2014 г. (ф. 221, кн. 1) зарегистрировано 4168 уголовных дел, за 2015 - 5173 (ф. 120, кн. 1), за первое полугодие 2016 г. - 2285 (ф. 120, кн. 101) [3].

Специфика наркопреступлений [4] требует принимать во внимание современный уровень развития технических средств и создавать новые подходы к организации этой работы на всех 
этапах деятельности органов дознания, начиная с производства первоначальных следственных действий и заканчивая дознанием в сокращенной форме по уголовному делу. На текущем этапе основными трудностями, препятствующими эффективному расследованию преступлений, связанных с незаконным оборотом наркотических, психотропных и сильнодействующих веществ, являются следующие:

а) распространенность наркотических веществ синтетического происхождения (амфетаминовой группы: эфедрона, PVP, MDPV; синтетических «аналогов тетрагидроканнабинола» (курительных смесей): «Спайса»; дизайнерских наркотиков, получивших неформальное обозначение «соли для ванн» [5]);

б) применение бесконтактных способов:

- распространения: использование обезличенных интернет-сайтов, анонимных сетей (в частности, Tor), доступ к которым обеспечивается посредством установки программного обеспечения, предоставляющего возможность задействовать технологии VPN (Virtual Private Network), защищенные протоколами шифрования (SSL) и сквозным шифрованием мессенджеров (Viber, WhatsApp, Telegram); доступ к ключам для их расшифровки для правоохранительных органов затруднен из-за территориального расположения серверов в европейских странах, а также политики конфиденциальности;

- оплаты: перечисление средств на однократно используемые номера сотовых телефонов, Яндекс-, Киви-кошельки;

- сбыта путем заранее создаваемых тайников, оборудованных в местах общего пользования; с помощью так называемых «закладок», помещаемых в плафоны ламп на лестничных переходах в многоквартирных жилых домах, закапываемых возле опорных столбов ЛЭП или деревьев; и пр.

Прежде чем решить вопрос о возбуждении уголовного дела, дознаватель вправе осуществить дополнительные проверочные действия и выяснить обоснованность информации, которая является поводом для возбуждения уголовного дела. Проверка материалов производится в следующих основных направлениях: получение результата исследования изъятых веществ; установление места происшествия, его осмотр, оценка результатов; получение сведений о способе совершения преступления, а также о лице, его совершившем; выявление очевидцев преступления, свидетелей. Нередко получение такой информации невозможно без подключения соответствующих ресурсов субъектов оперативно-разыскной деятельности. проверки:

На первоначальном этапе расследования возможно выдвинуть и следующие версии для

- обнаруженные наркотические средства приобретены подозреваемым у незнакомого ему лица;

- подозреваемый систематически приобретает у неустановленного лица, осуществляющего незаконный сбыт, наркотические, психотропные вещества [6].

Процесс рассмотрения сообщения о преступлении должен состоять из следующих этапов.

- Задержание и досмотр лица, в отношении которого предприняты проверочные действия. Задержание может производиться:

- по месту жительства;

- на участке с нелегальным посевом;

- на транспорте (в момент перевозки наркотика);

- на улице.

У задержанного необходимо изъять предметы, свертки, вещи, которые он может выбросить.

- Осмотр места происшествия. В случаях, когда задержание производится на улице, лицо может попытаться избавиться от объектов, которые могут скомпрометировать его в совершении незаконных действий. Если это произошло, следует зафиксировать расположение, например, свертка по правилам обзорной, узловой и детальной фотосъемки.

- Доставление проверяемого лица в опорный пункт либо районное управление внутренних дел.

- Направление запросов в оперативно-справочную картотеку ИЦ ГУ МВД (УМВД) и ГИЦ МВД РФ для получения установочных данных о личности проверяемого лица (привлечения к административной, уголовной ответственности, наличия судимости).

- Осмотр наркотических средств и упаковки, одежды, сотового телефона лица, в отношении которого производятся проверочные действия. Следует обратить внимание на наличие квитанции платежных терминалов, при помощи которых осуществляется оплата наркотических средств. В протоколе наряду с общими данными следует отразить и точный вес изъятого вещества, описать внешний вид упаковки, форму и все обозначения, обнаруженные на ней. 
- Осмотр мобильного телефона. Процедура прописана в ст. 176-180 УПК РФ. По делам данной категории осмотр средства связи - неотъемлемое следственное действие, результатом которого является получение ориентирующей, доказательственной информации [7]. Она может быть использована при выделении материалов и возбуждении отдельного уголовного дела по ст. 228.1 УПК РФ. В 38 \% проанализированных уголовных дел сотрудники производили осмотр телефона, не ограничиваясь лишь внешним описанием и фиксацией в протоколе его конструктивных особенностей (корпуса, модели устройства, аккумулятора, характеристик дисплея и отображенной на нем информации в активном режиме). Они фиксировали информацию, содержащуюся в журналах вызовов, входящих и исходящих SMS-сообщениях, IMEI-идентификационных номерах, а также сведения из переписки посредством сервисов для мгновенного обмена сообщениями (мессенджеров). В остальных 62 \% уголовных дел сотрудники, осуществлявшие предварительную проверку, ограничивались описанием внешнего строения, IMEI-номера, аккумуляторной батареи.

- Изъятие наркотических или психотропных веществ и образцов для сравнительного исследования (смывов с ладоней задержанного).

- Освидетельствование лица, в отношении которого производятся проверочные действия. При наличии у задержанного наркотического опьянения следует дождаться, когда он придет в нормальное состояние, что фриксируется в протоколе и документе о повторном освидетельствовании наркологом.

- Опрос проверяемого лица.

- Опрос очевидцев.

- Подготовка и направление запросов на получение профессиональной и бытовой характеристики проверяемого лица с целью установить данные о его личности (отношение к исполнению служебных обязанностей, образ жизни, бытовые условия).

- Подготовка и направление запросов в психоневрологический и наркологический диспансеры для установления особенностей личности потерпевшего и лица, в отношении которого производится проверка.

- Назначение экспертизы наркотических, психотропных или сильнодействующих веществ. Перед экспертом могут быть поставлены следующие вопросы:

а) является ли представленное на экспертизу вещество наркотическим средством, психотропным веществом или сильнодействующим фармацевтическим препаратом; если да, то каким именно;

б) к какому виду относятся представленные на экспертизу растения (порошки) и содержат ли они наркотические вещества;

в) каково содержание наркотически активных компонентов в веществе, представленном на экспертизу;

г) каким способом (промышленным или самодельным) изготовлено вещество, изъятое у подозреваемого;

д) имеются ли на объектах-носителях (тампонах, пакетах и т. п.), представленных на экспертизу, следы наркотических, психотропных или сильнодействующих средств; если да, то каких именно?

В таких случаях возможно предложить внедрить алгоритм типичных задач, которые необходимо решить экспертам. Так, при назначении судебной экспертизы материалов, веществ и изделий перед экспертом рекомендуется поставить следующие вопросы:

а) является ли данное вещество наркотическим средством; к какой группе средств оно относится; каким именно наркотическим средством оно является;

б) является ли данное вещество сильнодействующим; каким именно;

в) имеются ли на данных объектах следы наркотических и сильнодействующих средств; если имеются, то каких именно;

г) каково количество наркотического средства; каково содержание наркотически активных компонентов в данном веществе; именно;

д) содержат ли данные табачные изделия (их остатки) наркотические средства; какие

е) каким способом получены данные наркотические средства; можно ли описываемым способом получить наркотическое средство; может ли быть использована в качестве сырья для кустарного получения наркотического средства данная растительная масса (комплексно с судебно-ботанической экспертизой); является ли эта растительная масса отходами производства наркотического вещества (комплексно с судебно-ботанической экспертизой)?

По делам рассматриваемой категории также могут быть назначены следующие виды судебных экспертиз: ботанические, биологические, психиатрические, наркологические, медицинские.

- Принятие решения о возбуждении уголовного дела или отказе в возбуждении. 
Начало расследования в форме дознания состоит из следующих этапов.

- Осмотр проверочных материалов и вещественных доказательств.

- Допрос свидетелей. В данной категории преступлений могут присутствовать две группы допрашиваемых:

а) очевидцы задержания подозреваемого с поличным; соседи.

б) свидетели, работавшие вместе с подозреваемым (подозреваемыми), родственники,

- Поручение органу дознания произвести оперативно-разыскные мероприятия, направленные на установление лица, осуществлявшего сбыт наркотических веществ.

- Уведомление подозреваемого о возможности производства расследования в сокращенной форме.

- Допрос подозреваемого. В ходе процедуры дознавателю надлежит удостовериться в достоверности излагаемой им информации, зафиксировать новые сведения в случае, если они ранее не были озвучены при опросе.

- Принятие решения по поступившему от подозреваемого ходатайству о производстве дознания в сокращенной форме.

- Составление обвинительного постановления.

\section{Ссылки и примечания:}

1. Encouraging appropriate early guilty pleas: Models for discussion [Электронный pecypc]. URL: http://www.lawreform.justice.nsw.gov.au/Documents/Completed-projects/2010-onwards/Early-gulity-pleas/Consultation-paper/cp15_2.pdf (дата обращения: 10.08.2017)

2. Шаталов А.С. Проблемы алгоритмизации расследования преступлений : дис. ... д-ра юрид. наук. М., 2000. С. 183.

3. По данным Центра статистической информации ФКУ «ГИАЦ МВД России» от 27 июля 2016 г. № 3/167708159567.

4. Наркотические средства - это вещества синтетического или естественного происхождения, препараты, растения, включенные в Перечень наркотических средств, психотропных веществ и их прекурсоров, подлежащих контролю в Российской Федерации, утвержденный постановлением Правительства РФ от 30 июня 1998 г. № 681; в соответствии с законодательством РФ, международными договорами РФ, в том числе Единой конвенцией о наркотических средствах 1961 г.; ст. 1 федерального закона от 8 янв. 1998 г. № 3-Ф3 «О наркотических средствах и психотропных веществах». См. подробнее: Единая конвенция о наркотических средствах 1961 г. // Сборник действующих договоров, соглашений и конвенций, заключенных СССР с иностранными государствами. Вып. XXIII. М., 1970. С. 105-136 ; O наркотических средствах и психотропных веществах : федер. закон от 8 янв. 1998 г. № 3-Ф3 : с изм. и доп. // Собрание законодательства РФ. 1998. № 2. Ст. 219 ; Перечень наркотических средств, психотропных веществ и их прекурсоров, подлежащих контролю в Российской Федерации : постановление Правительства РФ от 30 июня 1998 г. № 681 : с изм. и доп. // Там же. № 27. Ст. 3198. Психотропными являются вещества синтетического или естественного происхождения, препараты, природные материалы, включенные в Перечень наркотических средств, психотропных веществ и их прекурсоров, подлежащих контролю в Российской Федерации, в соответствии с законодательством РФ, международными договорами РФ, в том числе Конвенцией о психотропных веществах 1971 г., Конвенцией ООН о борьбе против незаконного оборота наркотических средств и психотропных веществ 1988 г. См. подробнее: Конвенция $\mathrm{OOH}$ о борьбе против незаконного оборота наркотических средств и психотропных веществ 1988 г. // Сборник международных договоров СССР и Российской Федерации. Вып. XLVII. М., 1994. С. 133-157 ; Конвенция о психотропных веществах 1971 г. // Сборник действующих договоров, соглашений и конвенций, заключенных СССР с иностранными государствами. Вып. XXXV. М., 1981. С. 416-434.

5. См.: Синтетические наркотики: опасность распространения, их новые виды и аналоги [Электронный ресурс] : методическое пособие // ИАО Управления ФСКН России по Омской области. URL: http://antinark.omskportal.ru/ru/public/sitelist/antinark/profilaktika/PageContent/0/body_files/file16/20130604_Sintetieka_metoditschka.pdf (дата обращения: 10.08.2017) ; Шевырин В.А., Мелкозеров В.П. Дизайнерские наркотики. Криминалистическое исследование «структурных аналогов» пировалерона, производных наркотического средства N-метилэфедрона : информационное письмо для экспертных подразделений. Екатеринбург, 2011.

6. Брылев В.И., Сокол В.Ю., Лях Л.А. Проблемы выявления, раскрытия и расследования незаконного оборота наркотиков. Краснодар, 2008. С. 88-89.

7. Бутенко О.С. Криминалистические и процессуальные аспекты проведения осмотра мобильных телесонов в рамках предварительного следствия // Lex Russica. 2016. № 4 (113). С. 49-60 ; Козолупенко A.P. К вопросу о роли специалиста при осмотре мобильного устройства по уголовным делам, связанным с незаконным оборотом наркотиков // Сибирские уголовно-процессуальные и криминалистические чтения. 2016. № 5 (13). С. 57-69.

\section{References:}

Brylev, VI, Sokol, VYu \& Lyakh, LA 2008, Problems of detection, disclosure and investigation of drug trafficking, Krasnodar, pp. 88-89, (in Russian)

Butenko, OS 2016, 'Forensic and procedural aspects of the examination of mobile phones in the preliminary investigation', Lex Russica, no. 4 (113), pp. 49-60, (in Russian).

'Convention on Psychotropic Substances of 1971' 1981, Sbornik deystvuyushchikh dogovorov, soglasheniy i konventsiy, zaklyuchennykh SSSR s inostrannymi gosudarstvami, Issue XXXV, Moscow, pp. 416-434, (in Russian).

Encouraging appropriate early guilty pleas: Models for discussion 2017, viewed 10 August 2017, <http://www.lawreform.justice.nsw.gov.au/Documents/Completed-projects/2010-onwards/Early-gulity-pleas/Consultation-paper/cp15_2.pdf>.

Kozolupenko, AR 2016, 'The role of an expert during the examination of the mobile device in drug trafficking crimes', Sibirskiye ugolovno-protsessual'nyye i kriminalisticheskiye chteniya, no. 5 (13), pp. 57-69, (in Russian).

Shatalov, AS 2000, Problems of developing a crime investigation algorithm, D.Phil. thesis, Moscow, p. 183, (in Russian). 
Shevyrin, VA \& Melkozerov, VP 2011, Designer drugs. A forensic study on structural analogues of pyrovalerone, N-methylephedron derivatives: an information letter, Yekaterinburg, (in Russian).

'Single Convention on Narcotic Drugs, 1961' 1970, Sbornik deystvuyushchikh dogovorov, soglasheniy i konventsiy, zaklyuchennykh SSSR s inostrannymi gosudarstvami, Issue XXIII, Moscow, pp. 105-136, (in Russian).

'Synthetic drugs: the danger of proliferation, their new types and analogues: manual', IAO Upravleniya FSKN Rossii po Omskoy oblasti, viewed 10 August 2017, <http://antinark.omskportal.ru/ru/public/sitelist/antinark/profilaktika/PageContent/0/body_files/file16/20130604_Sintetieka_metoditschka.pdf>, (in Russian).

'United Nations Convention against Illicit Traffic in Narcotic Drugs and Psychotropic Substances of 1988' 1994, Sbornik mezhdunarodnykh dogovorov SSSR i Rossiyskoy Federatsii, Issue XLVII, Moscow, pp. 133-157, (in Russian). 